\title{
SABERES PARA ENSINAR MATEMÁTICA E A EXPERTISE DOCENTE NA OBRA DE FONTOURA
}

\author{
Rogerio dos Santos Carneiro ${ }^{1}$ \\ Neuza Bertoni Pinto ${ }^{2}$
}

\begin{abstract}
RESUMO: Nesta pesquisa realizamos uma breve análise da base teórica aperfeiçoada pelo Grupo de Pesquisa da História da Educação Matemática no Brasil (GHEMAT), fundamentada por referenciais da Equipe de Pesquisa em História das Ciências da Educação (ERHISE), Universidade de Genebra, a qual alicerça as discussões sobre os saberes pertinentes à docência e o expert em educação, com o intuito de perscrutar os saberes para ensinar matemática, que estão presentes na Metodologia do Ensino Primário, de Afro do Amaral Fontoura. Como resultado deste estudo encontramos alguns sinais da expertise de Fontoura, pois desempenhou um papel fundamental como organizador de manuais que orientaram a formação inicial de professores. E os saberes matemáticos elementares para ensinar, identificados na obra analisada, acompanham o ideário da Escola Nova, em relação aos métodos de ensino. Cada vez mais se notam as estreitas relações das Ciências da Educação, condicionando as atividades ao desenvolvimento das potencialidades dos alunos.
\end{abstract}

Palavras-chave: Saberes Docentes. Didática Especial. Ensino de Matemática. Especialista em Educação.

\section{KNOWLEDGE TO TEACH MATHEMATICS AND TEACHING EXPERTISE IN THE WORK OF FONTOURA}

ABSTRACT: In this research we make a brief analysis of the theoretical basis perfected by the Research Group on the History of Mathematical Education in Brazil (GHEMAT), based on references from the Research Team on History of Educational Sciences (ERHISE), University of Geneva, which underlies the discussions about the knowledge relevant to teaching and the education expert, with the intention of examining the knowledge to teach mathematics which are present in the Methodology of Primary Education, Afro do Amaral Fontoura. As a result of this study we find some signs of Fontoura expertise, since it played a fundamental role as organizer of manuals that guided the initial formation of

1 Mestre em Educação Matemática. Doutorando em Educação em Ciências e Matemática da Universidade Federal de Mato Grosso (UFMT). Cuiabá - MT/Brasil. Docente da Universidade Federal do Tocantins (UFT) Campus de Araguaína - TO/Brasil. E-mail: rogerioscarneiro@gmail.com

2 Doutora em Educação. Docente da Universidade Federal de Mato Grosso (UFMT). Cuiabá-MT/Brasil. E-mail: neuzabertonip@gmail.com 
teachers. And the elementary mathematical knowledge to teach identified in the work analyzed, accompanying the ideas of the New School, in relation to teaching methods increasingly noticed the close relations of the Sciences of Education, conditioning the activities to the development of the potential of students.

Keywords: Knowledge Teacher. Special Didactics. Mathematics Teaching. Education Specialist.

\section{SABERES PARA ENSEÑAR MATEMÁTICA Y LA EXPERIENCIA DOCENTE EN LA OBRA DE FONTOURA}

RESUMEN: En esta investigación realizamos un breve análisis de la base teórica perfeccionada por el Grupo de Investigación de Historia de la Educación Matemática en Brasil (GHEMAT Brasil), fundamentada por referenciales del Equipo de Investigación en Historia de las Ciencias de la Educación (ERHISE), Universidad de Ginebra, que fundamenta las discusiones sobre los saberes pertinentes a la docencia y el experto en educación. Con el fin de escrutar los saberes para enseñar matemática, que están presentes en la Metodología de la Enseñanza Primaria, de Afro do Amaral Fontoura. Como resultado de este estudio encontramos algunas señales de la experiencia de Fontoura, pues desempeñó un papel fundamental como organizador de manuales que orientaron la formación inicial de profesores. Y los saberes matemáticos elementales para enseñar identificados en la obra analizada, acompañan el ideario de la Escuela Nueva, en relación a los métodos de enseñanza, cada vez más se notan las estrechas relaciones de las Ciencias de la Educación, condicionando las actividades al desarrollo de las potencialidades de los alumnos.

Palabras clave: Conocimientos Docentes. Didáctica Especial. Enseñanza de Matemática. Especialista en Educación.

\section{Introdução}

Neste texto vislumbra-se a reflexão sobre alguns aspectos relacionados aos saberes necessários à docência. Com o intuito de obter uma compreensão histórica dos saberes objetivados presentes em manuais pedagógicos ${ }^{3}$ destinados a formação inicial do professor que ensina matemática, o presente estudo fundamenta-se na concepção da história da educação matemática evidenciando

A necessidade de trazer de volta, à mesa de discussão, o passado da educação matemática, em termos de sua representação, não tem caráter saudosista. Os rastros desse passado, presentes na contemporaneidade da educação matemática, indicam a necessidade

3 Estamos chamando de "manuais pedagógicos", os livros didáticos destinados à formação inicial de professores. 
de compreender historicamente como as descontinuidades de outros tempos históricos deixaram marcas nas práticas pedagógicas presentes nas salas de aula da atualidade. Mais que isso: é imperativo ampliar o debate presente sobre a educação matemática trazendo a história da educação matemática como um participante ativo da discussão (VALENTE, 2011, p. 2).

O pesquisador Valente (2007, p. 31), com base na visão de Antoine Prost $^{4}$, nos traz que "os fatos históricos são constituídos a partir de traços, de rastros deixados no presente pelo passado". Sendo assim, para produzir a história da educação matemática é importante a aproximação com o campo da história, tendo como finalidade atribuir sentido ao fazer historiográfico na perspectiva histórico-cultural. Nesse delineado, pode-se mencionar que essa aproximação advém do campo da história, no qual há necessidade de levantar questionamentos para que possamos recolher registros do passado e, a partir daí, a busca do entendimento desses fatos.

O autor Certeau (2007) aborda a história com um "novo olhar" e também com um "novo dizer" que contribuiu para a renovação da prática historiográfica, ressaltando que o gosto do historiador liga suas ideias aos lugares de onde fala. A construção dos fatos históricos parte de uma análise da realidade e se articula com a produção socioeconômica, política e cultural.

A articulação da história com um lugar é a condição de uma análise da sociedade. [...] Levar a sério o seu lugar não é ainda explicar a história. Mas é a condição para que alguma coisa possa ser dita sem ser nem legendária (ou "edificante"), nem a-tópica (sem pertinência). Sendo a denegação da particularidade do lugar o próprio princípio do discurso ideológico, ela exclui toda a teoria (CERTEAU, 2007, p. 77).

O historiador produz seu trabalho a partir do presente, das preocupações de sua realidade, fazendo de seu discurso um "discurso particularizado", que tem um emissor, o historiador e um destinatário, seja ele qual for: a academia, a sociedade de forma geral ou um grupo específico (CERTEAU, 2007).

A história das disciplinas escolares contribui para desnaturalizar representações sobre

4 Valente (2007, p. 29) texto escrito com fundamentações "no curso de história do professor e historiador Antoine Proust, dado na Sorbonne, em Paris, e transformado em livro, em 1996, sob o título Douze leçons sur l'histoire". 
a matemática escolar que ainda estão inseridas em Unidades Educacionais. Segundo Pinto (2014, p. 129) "uma forte representação ainda presente na sociedade é ser considerada por muitos como um saber para poucos, aos que nascem com 'dom' para matemática, representação, em geral reforçada nos meios escolares"

O interesse pelos saberes necessários à docência, por uma visão histórica, surge a partir dos estudos que vêm sendo desenvolvidos no Grupo de Pesquisa da História da Educação Matemática no Brasil (GHEMAT)5 , que atualmente desenvolve um amplo projeto sobre saberes profissionais do professor que ensina matemática nos primeiros anos escolares, utilizando um referencial teórico da Equipe de Pesquisa em História das Ciências da Educação (ERHISE), Universidade de Genebra, Suíça6 ${ }^{6}$ Para a equipe suíça, os saberes da docência, denominados de saberes profissionais do professor, são constituídos pela articulação dos saberes a ensinar, ou seja, saberes disciplinares advindos das ciências de referência e dos saberes para ensinar, advindos das ciências da educação.

Os saberes necessários para formação de professores que ensinam matemática, em especial os docentes dos primeiros anos escolares, referem-se ao conjunto de saberes da profissão, como uma matemática para o exercício da docência resultante, portanto, da fusão de saberes advindos da ciência matemática e da ciência da educação que, ao passar por complexos processos de objetivação, transformam-se em saberes profissionais para ensinar matemática nos primeiros anos escolares. Saberes que os livros, ora denominados de manuais pedagógicos, fontes constituídas em várias investigações históricas, pelo fato de trazerem vestígios "do que" e "do como" se ensinou a matemática escolar, têm contribuído para o traçado da história da cultura escolar e da história das disciplinas, em especial da história da educação matemática.

No que se refere a essa fonte histórica em nossa pesquisa, analisamos o livro

5 O GHEMAT - Grupo de Pesquisa de História da Educação Matemática no Brasil foi criado em 2000. O Grupo, cadastrado no Diretório de Grupos de Pesquisas do CNPq, tem como líderes os professores Wagner Rodrigues Valente (UNIFESP - Campus Guarulhos) e Neuza Bertoni Pinto (REAMEC).

6 Para maiores informações sobre 0 grupo e seus estudos consulte-se: https://www.unige.ch/fapse/recherche/groupes/ssed/culture-organisation/erhise/. Inúmeros desses estudos estão disponibilizados na obra publicada no Brasil: "Saberes em (trans)formação: tema central da formação de professores", de autoria de Rita Hofstetter e Wagner Rodrigues Valente. 
Metodologia do Ensino Primário, de Afro do Amaral Fontoura, que à época também era considerado uma Didática Especial, no caso, Didática da Matemática, utilizado no Brasil e editado entre os anos de 1955 a 1961, com intenção de "interrogá-lo" e tentar compreender como os saberes para ensinar matemática se apresentaram neste material em período em que os ideais da escola nova pareciam estar consolidados no ensino primário. Trata-se de um momento em que a literatura educacional que circula nos cursos de formação anuncia transformações nos processos de ensinar e aprender matemática, em superação ao método intuitivo, configurado nas Lições de Coisas, modernidade pedagógica que marcou presença na Aritmética da escola primária em período anterior à década de 1930.

Com o advento de novas propostas pedagógicas trazidas pelo Movimento da Escola Nova para o ensino da Aritmética, nos primeiros anos escolares, os manuais didáticos encarregam-se de difundi-las aos professores, informando sobre as transformações, a renovação dos métodos, processos e procedimentos de ensinar. Nos anos de 1960, alterações trazidas por um novo movimento (o movimento da matemática moderna) impactou o ensino da matemática escolar.

Segundo Lussi Borer (2017), há uma evolução que leva à especialização dos saberes disciplinares na formação de professores, transformando a Didática Geral em didáticas especiais ligadas às diferentes disciplinas, ocasionando o desenvolvimento dos saberes para ensinar por meio da constituição progressiva de um campo disciplinar das Ciências da Educação. A partir desse cenário de mudanças, indagamos no presente estudo: que saberes para ensinar matemática constam na Metodologia do Ensino Primário, de Afro do Amaral Fontoura? O referido autor pode ser considerado um expert na educação brasileira?

Partindo do princípio de que as transformações ocorridas no período a ser investigado geraram novos saberes profissionais e considerando, conforme preconiza o referencial teórico da equipe suíça, de que os saberes para ensinar não se desarticulam dos saberes a ensinar, analisaremos como tais articulações marcaram presença no manual mencionado e favoreceram a compreensão do que foi considerado como saberes indispensáveis para ensinar matemática nos anos iniciais de escolarização. 


\section{O "historiador" e as representações de cultura escolar}

A produção dos pesquisadores que se voltam à história das disciplinas escolares, que se pautam em tal base teórico-metodológica, representa tentativas de fornecer subsídios para o estudo das culturas escolares numa perspectiva histórica. A respeito da condução da investigação da cultura escolar, Julia (2001, p. 10) indica que "[...] esta cultura escolar não pode ser estudada sem a análise das relações conflituosas ou pacíficas que ela mantém, a cada período de sua história, com o conjunto das culturas que lhes são contemporâneas". Portanto, as práticas escolares são modificadas e inovadas conforme as alterações do público e das necessidades socioculturais, que impõem a mudança dos conteúdos a serem ensinados. Cada novo público oriundo de culturas diversas influencia os contextos escolares e, consequentemente, é influenciado pelos mesmos.

O historiador Marc Bloch, ainda em fins da primeira metade do século XX, procurava redefinir o que seria a história, e qual é o ofício do historiador, assinalando também que este deve "saber falar, no mesmo tom, aos doutos e aos estudantes" (BLOCH, 2002, p. 41). Nesse sentido, o autor, enfatiza a obrigação do historiador em difundir, explicar e esclarecer, obrigação que prescinde não somente da academia, mas, sobretudo, do espaço escolar.

Tratar os documentos de uma determinada época como fontes para a produção da história da educação matemática, entendendo-a como especialização da história da educação é "alargar o entendimento de como se dá, na história, o processo de escolarização dos diferentes saberes e, em particular, da matemática, tomando como ponto de partida um instrumental teórico-metodológico utilizado pelos historiadores" (VALENTE, 2004, p. 82). Com relação à investigação histórica das disciplinas escolares, o historiador André Chervel argumenta a respeito da possibilidade que as disciplinas oferecem em romper com as pedagogias tradicionais.

\footnotetext{
A história das disciplinas escolares expõe à plena luz a liberdade de manobra que tem a escola na escolha de sua pedagogia. Ela depõe contra a longa tradição que, não querendo ver nas disciplinas ensinadas senão as finalidades que são efetivamente a regra imposta, faz da escola o santuário não somente da rotina mas da sujeição, e do mestre, o agente impotente de uma didática que lhe é imposta do exterior (CHERVEL, 1990, p. 193).
} 
Entretanto, no que tange à análise da cultura que a escola transmite a seus alunos, comporta além da análise histórico-social, o desmembramento propriamente pedagógico ou interno, que engloba o programa escolar, com as finalidades educativas que lhe são confiadas, o conteúdo aprendido e também objetivos não explicitados, decorrentes dos mecanismos didáticos postos em ação para o ensino, isto é, o modo como os conceitos são aprendidos.

A análise criteriosa da história cultural, esclarece o historiador francês Roger Chartier, é importante para identificar o modo como, em diferentes lugares e momentos, uma realidade social é construída, pensada, dada a ler. Portanto, ao voltar-se para a vida social, esse campo pode tomar por objeto as formas e os motivos das suas representações e pensálas como análise do trabalho de representação das classificações e das exclusões que constituem as configurações sociais e conceituais de um tempo ou de um espaço. No entanto, a história cultural deve ser entendida como o estudo dos processos com os quais se constrói um sentido, uma vez que as representações podem ser pensadas como "[...] esquemas intelectuais, que criam as figuras graças às quais o presente pode adquirir sentido, o outro tornar-se inteligível e o espaço ser decifrado" (CHARTIER, 1990, p. 17).

Segundo Julia (2001), a respeito da história das produções escolares,

Ela tenta identificar, tanto através das práticas de ensino utilizadas na sala de aula como através dos grandes objetivos que presidiram a constituição das disciplinas, o núcleo duro que pode constituir uma história renovada da educação. Ela abre, em todo caso, para retomar uma metáfora aeronáutica, a "caixa preta" da escola, ao buscar compreender o que ocorre nesse espaço particular (p. 13).

Sendo assim, Julia (2001) nos traz que um estudo na perspectiva da história cultural deve considerar como aspecto principal a identificação do que será tomado como fontes, sobre as quais sugere também o questionamento de seu rigor. A respeito da produção do historiador, Bloch (2002) ressalta que, ao escrever esse tipo de texto, o pesquisador precisa atentar-se para a própria nomenclatura da história que é fornecida de forma ultrapassada diante da época vivenciada pelo escritor.

A história recebe seu vocabulário, portanto, em sua maior parte, da própria matéria de seu estudo. Aceita-o, já cansado e deformado por longo uso; ambíguo, aliás, não raro desde a origem, como todo sistema 
de expressão que não resulta do esforço severamente combinado dos técnicos" (BLOCH, 2002, p. 136).

O historiador depara-se com a dificuldade em descrever com linguagem atualizada, podendo distorcer o acontecimento de outra época, ou interpretar com sentido errado uma palavra, ou expressão, que não existe mais ou cujo significado se alterou com o passar dos anos ou espaços culturais.

Julia, ao afirmar que "[...] o historiador sabe fazer flechas com qualquer madeira" (JULIA, 2001, p. 17), aponta a necessidade de que aqueles que pesquisam ou que venham a pesquisar disciplinas escolares, ou cultura escolar, devem utilizar várias fontes e métodos que possam completar as lacunas originadas pela escassez de fontes que remetam ao cotidiano escolar. Destarte, o historiador de disciplinas escolares tem como função estudar as variações da Matemática e da cultura escolar como um todo, sem fazer restrições no âmbito do nível de escolarização ligado ao ensino disciplinar. Sendo assim, nossa pesquisa estará se preocupando em tentar levantar como se processou, em cada momento, a organização lógica e metodológica de temas específicos.

\title{
Os saberes profissionais necessários a formação do docente que ensina matemática
}

A profissão docente está internamente relacionada às disciplinas que, por sua vez, dão sentido aos atos da docência. Assim, os saberes envolvidos nessa profissão apresentam-se formalizados e sistematizados nas diferentes disciplinas dos cursos de formação. Reportandose ao cenário suíço, Lussi Borer (2017) afirma que

\begin{abstract}
O período estudado testemunha assim uma dupla evolução conjunta de saberes disciplinares no interior das formações para o ensino ministradas nos cantões universitários de língua francesa. Os saberes disciplinares se especializam cada vez mais no interior das universidades, gerando uma distância crescente com os saberes $a$ ensinar, especialmente no nível secundário, uma distância que deve ser preenchida pela formação de professores. Esta evolução leva a especialização progressiva da didática geral em didáticas especiais ligadas às diferentes disciplinas (p. 194).
\end{abstract}

É importante observar que, apesar da legitimidade obtida pelas Ciências da Educação 
no campo da formação, como observam estudos desenvolvidos pela equipe suíça, "toda instituição de formação se define pelos saberes a ensinar que a especificam" (HOFSTETTER; SCHNEUWLY, 2017, p. 137). Segundo esses autores, para a compreensão dos saberes profissionais se torna necessária uma reflexão dos saberes envolvidos nas disciplinas, consideradas construções sócio históricas da profissão docente.

Antes de tratar das especificidades dos saberes, convém esclarecer a distinção que a Equipe de Pesquisa em História das Ciências da Educação (ERHISE) reconhece entre conhecimento e saber. Tal discernimento é alicerçado em Pastré, Vergnaud e Mayen (2006 apud HOFSTETTER; SCHNEUWLY, 2017), os quais consideram a escola como um espaço de "aprendizagem intencional", afirmam que:

Para ajustar-se a todos os tipos de situações, um sujeito dispõe dos recursos construídos no passado e adquiridos da experiência. Mas ele dispõe, sobretudo, de uma capacidade de criar novos recursos, para reorganização daqueles já adquiridos. [...] por um lado, os nossos conhecimentos são recursos que utilizamos para resolver os nossos problemas. Por outro lado, estes mesmos conhecimentos podem ser encarados em si próprios, de modo a que se possa identificar neles mesmos propriedades, tornando-se assim saberes. Estes constituem conjuntos de enunciados coerentes e reconhecidos por uma comunidade científica ou profissional. Adquirindo então um lugar central na aprendizagem intencional (PASTRÉ; VERGNAUD; MAYEN, 2006, p. 156 apud HOFSTETTER; SCHNEUWLY, 2017, p. 117-118).

Nesse aspecto, os saberes escolares constituem um conjunto de conhecimentos que são produzidos, reconhecidos e validados no âmbito escolar. No que diz respeito à formação dos profissionais do ensino, Hofstetter e Schneuwly (2017, p. 131-132) concebem dois tipos de saberes, "os saberes a ensinar, ou seja, os saberes que são os objetos do seu trabalho; e os saberes para ensinar, em outros termos os saberes que são as ferramentas do seu trabalho".

Os pesquisadores Bertini, Morais e Valente (2017, p. 12) afirmam que "as escolas normais oferecem uma formação tanto geral como profissional". Nessa perspectiva, esses autores apontam que a formação geral era ministrada em nível secundário e era responsável por ensinar os conhecimentos das disciplinas escolares. A formação profissional teria o papel de transmitir saberes com origem das ciências da educação. Portanto, na formação geral seriam adquiridos os saberes a ensinar, enquanto na formação profissional proporcionariam 
o desenvolvimento dos saberes para ensinar.

Tendo como foco a formação profissional inicial de um professor, os pesquisadores Hofstetter e Schneuwly (2017, p. 133-134), afirmam que "formar, como qualquer atividade humana, implica dispor de saberes para sua efetivação, para realizar essa tarefa, esse ofício específico. E esses saberes constituem ferramentas de trabalho, neste caso saberes para formar ou saberes para ensinar".

A concepção acadêmica em torno da formação, de acordo com os pesquisadores suíços, vem ganhando um viés com a existência de vertentes encaminhadas em direções contrárias: na direção "instrumentalista", na qual a formação é articulada aos conhecimentos cotidianos e a aquisição do saber é individual, ocorrendo de acordo com as próprias necessidades do indivíduo. Na direção "neoconservadora" o saber para ensinar e o saber a ensinar são, de certa forma, os mesmos saberes, logo não há a necessidade de se transformar os saberes para que estes sejam ensináveis, Hofstetter e Schneuwly (2017). Desse modo, seguindo por essa direção, os saberes para ensinar seriam inúteis.

Especificamente no caso da matemática, segundo Santos e Lins (2016 apud VALENTE, 2016), existem duas concepções sobre a matemática na formação dos professores: uma diz que existe somente uma matemática, ou seja, a matemática do nível superior se difere da matemática da escola básica apenas pelo estágio de complexidade em que se ministram os conteúdos. E "quem domina o mais avançado, logicamente terá ciência do menos avançado. Finalmente, tem-se uma única matemática dosada em vários anos e graus escolares" (VALENTE, 2016, p. 462). A outra concepção trata da existência de diferentes matemáticas, "a matemática acadêmica" e a "matemática escolar", sendo que ambas têm necessidades e finalidades distintas.

Considerando a formação dos professores dos primeiros anos, temos, historicamente, a formação pelas escolas normais, mais tarde pelos cursos de habilitação específica de magistério e atualmente pelas escolas de nível superior. Com relação à formação pelas escolas normais, inicialmente, os saberes a ensinar, advindos das disciplinas escolares, caracterizavam as instituições e os saberes profissionais, os saberes para ensinar matemática, eles estavam sob a responsabilidade do diretor da instituição ou de profissionais levados pelo diretor para 
palestras pedagógicas na escola (VALENTE, 2017).

Salientando a importância dos estudos históricos sobre os saberes profissionais para as discussões atuais a respeito da formação de professores que ensinam matemática, Valente (2017) afirma que as questões ligadas à matemática a ensinar são muito relevantes na formação dos professores, mas tal aspecto da formação não é identitário do educador matemático. A natureza dessa profissão filia-se mais intimamente aos saberes para ensinar matemática.

\section{Saberes para ensinar matemática na Metodologia do Ensino Primário de Afro do Amaral Fontoura}

Antes de examinarmos, na obra do autor selecionado, os saberes para ensinar matemática nos primeiros anos escolares, vamos tentar trazer uma resposta a um questionamento que surgiu: quem foi Afro do Amaral Fontoura? Esse autor se constitui como expert para a formação de professores? Em especial para a formação de professores que ensinam matemática? Antes de tentarmos obter elementos para uma possível resposta às questões levantadas neste subitem, precisamos discutir, mesmo que superficialmente, a base teórica que fundamenta uma tentativa de determinar a expertise do especialista em educação.

[...] o sentido amplo dado à noção de expertise: uma instância, em princípio reconhecida como legítima atribuída a um ou a vários especialistas - supostamente distinguidos pelos seus conhecimentos, atitudes, experiências - a fim de examinar uma situação, de avaliar um fenômeno, de constatar fatos. Esta expertise é solicitada pelas autoridades do ensino tendo em vista a necessidade de tomar uma decisão. A solicitação de expertise participa decididamente da produção de novos saberes no campo pedagógico (HOFSTETTER; SCHNEUWLY; FREYMOND, 2017, p. 57).

Visualiza-se o expert em educação como um indivíduo que conhece perfeitamente o ofício docente e nele se destacou, tendo um papel fundamental como organizador de, entre pares na instituição, assim como a circulação dos saberes profissionais lá produzidos. Como Hofstetter e Schneuwly (2017), consideramos a noção de expertise como aquela reconhecida como legítima, atribuída a um ou a vários especialistas. Esses especialistas são distinguidos 
por seus conhecimentos, atitudes, experiências na análise de uma situação, na avaliação de um fenômeno, na constatação de fatos, ou seja, são experts porque conhecem bem seu ofício e nele se destacam, aliando saberes da profissão com as da disciplina.

No intuito de responder as indagações levantadas no início desta secção, buscamos algumas fontes acadêmicas, as quais nos resultaram um "curriculum vitae" sem muitos detalhes biográficos e da produção científica. Constatada a ausência de dados referentes ao homem, ao professor e ao autor Afro do Amaral Fontoura, procuramos identificar pesquisas nas quais o educador pudesse ter-se constituído como objeto de investigação de estudiosos brasileiros. Dito isso, conseguimos levantar que a data de nascimento foi no ano de 1912, vindo a falecer em 1987. A sua formação inicial no Magistério é um dado pesquisado e constatado por Meucci (2007). Alguns anos depois, já formado na Faculdade de Filosofia da Universidade do Brasil, passou a dar aulas de sociologia e serviço social nas principais faculdades fluminenses.

Foi professor na Pontifícia Universidade Católica do Rio de Janeiro, Universidade do Estado do Rio de Janeiro, Faculdade de Serviço Social do Distrito Federal, Faculdade de Filosofia Santa Úrsula, Escola do Comando Maior do Exército. Presidente da Associação brasileira das Escolas Normais na década de 1960, organizou algumas Semanas de Educação em diversos estados e municípios brasileiros. No ano de 1966, presidiu o Primeiro Congresso Brasileiro de Ensino Normal, realizado no estado do Rio de Janeiro.

Ainda segundo Meucci (2007), o primeiro manual publicado por Amaral Fontoura, tudo indica, foi Programa de Sociologia, editado pela primeira vez em 1940 e reeditado em 1942, 1943 e 1944 pela editora Globo. Posteriormente, sob nova denominação - Introdução à Sociologia - foi reeditado pela mesma editora cinco vezes no período de 1945 e 1973 . De forma mais minuciosa, a pesquisadora indica as obras que foram publicadas por Fontoura:

\footnotetext{
"Programa de sociologia", "Introdução de sociologia", "Sociologia educacional", "Fundamentos da educação", "Metodologia do ensino primário", "Psicologia geral", "O ruralismo: base da economia nacional", "Dicionário Enciclopédico Brasileiro", "O drama no campo", "Introdução ao serviço social", "Aspectos da vida rural brasileira", "Fundamentos da Educação", "Introdução ao Serviço Social", "Psicologia Educacional", "O planejamento no ensino primário", "Didática especial da primeira série", "Prática de ensino", "Didática
} 
geral", "Manual de testes", "Educação cívica e calendário cívico brasileiro" (MEUCCI, 2007, p. 57).

Assim, podemos constatar um conjunto de obras publicadas por Amaral Fontoura, ficando evidenciado que o mesmo estudou e abordou temas diversos, entre os quais destacamos: sociologia, psicologia, filosofia, serviço social, didática, prática de ensino, metodologia do ensino. Essa diversidade produtiva indica-nos uma formação intelectual ampla e geral.

Dentre esse leque de produção, vamos nos ater à obra Metodologia do Ensino Primário. Como pode ser verificado na Figura 1, era indicada para o 2ㅇ e 3 anos do Curso Normal. A edição que temos é 6ạ , datada de 1961, sendo o terceiro volume da Série I - A Escola Viva - Biblioteca Didática Brasileira7. Possui 449 páginas e está disponibilizada no Repositório do Grupo de Pesquisa de História da Educação Matemática (GHEMAT) ${ }^{8}$. França destaca a importância da Biblioteca Didática Brasileira para a formação dos professores primários.

Ainda posso inferir que a coleção obteve ampla circulação em virtude a uma teia de contextos de sustentação. Entre eles: seus autores, em sua grande maioria, professores de escolas normais, que gozavam de prestígio entre os futuros docentes; o número expressivo de edições atingido pela coleção, facilitando a aceitação das propostas reformistas; e a posição de poder ocupada por Fontoura, no momento das reformas (FRANÇA, 2016, p. 41).

Sobre a direção da referida Biblioteca, França cita pronunciamento da Editora Aurora, acerca do Professor Afro do Amaral Fontoura:

Para ter certeza e atingir tais objetivos, a editora Aurora entregou a direção da Biblioteca Didática Brasileira a um dos educadores mais categorizados no assunto: o professor Amaral Fontoura, reputado Técnico de educação, que há muitos anos se vem debatendo por essa renovação no Ensino Normal. Professor de várias faculdades - bem como da notável Universidade Católica do Rio de Janeiro - delegado do

7 Segundo Fontoura (1961), a coleção Biblioteca Didática Brasileira, da Editora Aurora, dirigida por Afro do Amaral Fontoura, foi organizada por meio das seguintes séries: Série I (A escola viva); Série II (Legislação Brasileira de Educação); Série III (Livros texto para crianças); Série IV como aprender brincando (material didático).

8 Segundo Costa e Valente (2015, p. 101) - "o Repositório se alinha à sub-comunidade História da Educação Matemática, aninhada ao Centro de Ciências da Educação da UFSC. Trata-se de um repositório virtual, aberto e institucionalizado, especificamente para armazenar fontes diversas, ensaios e pesquisas voltadas para a História da Educação Matemática. Poderá ser consultado a partir de qualquer dispositivo com acesso à internet no seguinte endereço: http://repositorio.ufsc.br/handle/123456789/1769". 
governo junto a várias Escolas Normais, professor de inúmeros cursos de aperfeiçoamento para professores, que consegue reunir duas qualidades que raramente se encontram juntas: profundo conhecimento teórico da Pedagogia, ao lado de um admirável espírito prático e objetivo (EDITORA AURORA, 1960, p. XIII apud FRANÇA, 2016, p. 41).

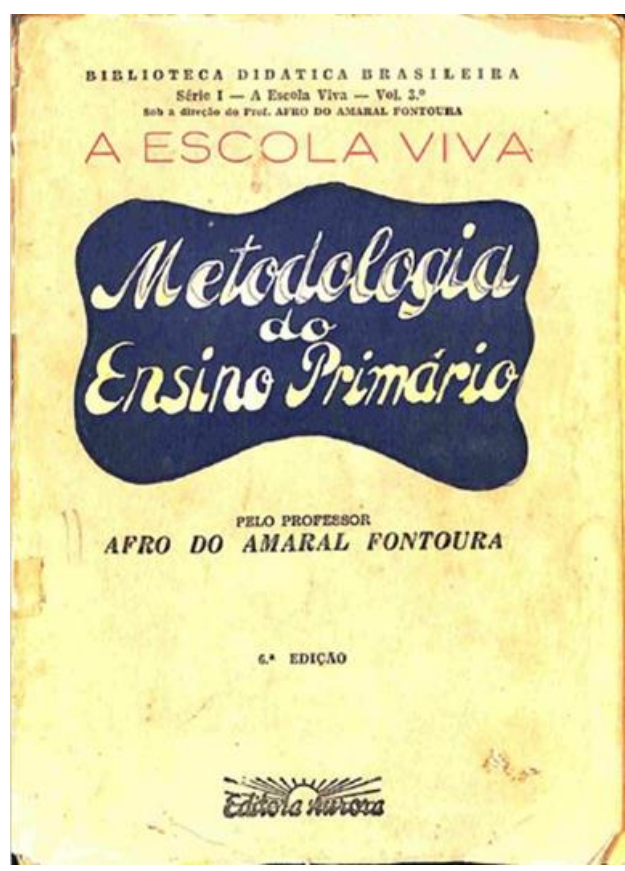

$$
\begin{aligned}
& \begin{array}{c}
\text { BIBLIOTECA DIDATICA BRASILE IRA } \\
\text { Serio I-A Escola Vira-Vol, } 30^{\circ}
\end{array} \\
& \text { SOB A DHAEÇTO do PRoY. AMARAL FONTOURA }
\end{aligned}
$$

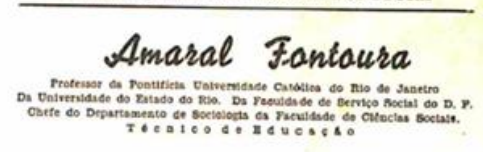

Figura 1 - Capa e Folha de Rosto do manual Metodologia do Ensino Primário.

Fonte: Fontoura (1961, p. I-II).

Esse livro foi dividido em seis seções, em que a Parte I - Metodologia da Linguagem, aborda o ensino de leitura, escrita, gramática, composição e literatura. A Parte II Metodologia da Matemática, descreveremos a seguir com a análise, a Parte III - Metodologia das Ciências Sociais traz o ensino de geografia, história e ciências sociais. Enquanto as Partes IV e V referem-se à Metodologia das Ciências Naturais e à Metodologia do desenho e Trabalhos Manuais, respectivamente.

$\mathrm{Na}$ introdução da parte que é objeto de nossa análise, a Metodologia da Matemática, o autor exibe uma ficha resumo, com doze itens que são explanados no decorrer do texto, são eles: Conceito, importância e compreensão; A Matemática e a Nova Pedagogia; Psicologia Aritmética; Objetivos; Motivação; Direção da Aprendizagem da Aritmética; Fixação da Aprendizagem; Verificação da Aprendizagem; Exercícios e problemas e Jogos e aparelhos, como pode ser verificado na Figura 2. 
PARTE II METODOLOGIA DA MATEMÃTICA

CAPítulo IV Metodologia da Matemática

Ficha-resumo:

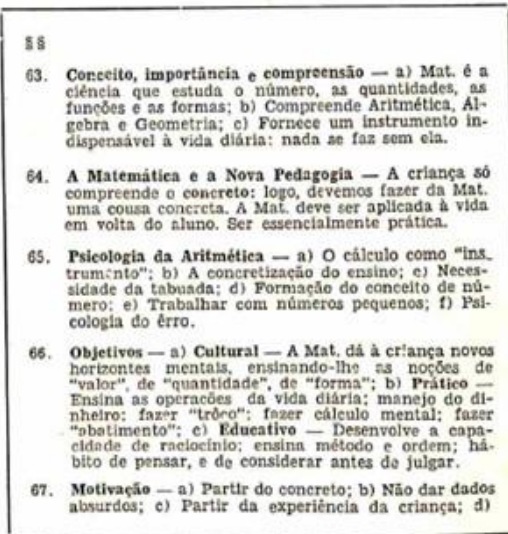

198

AFRO DO AMARAL FONTOURA

Ficha-resume (conciusão):

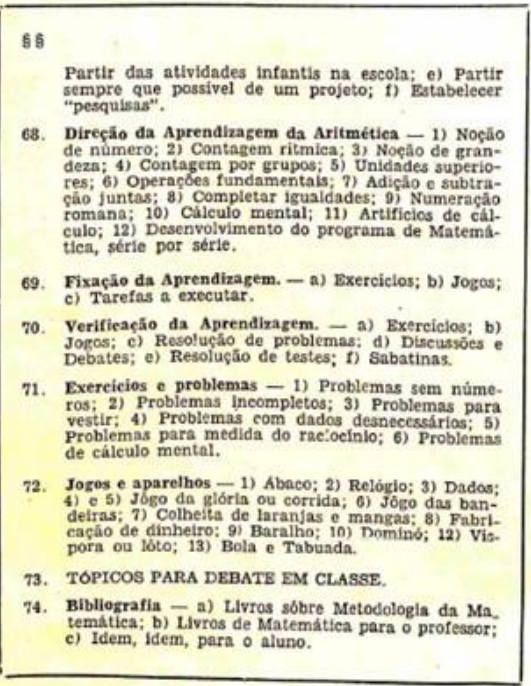

Figura 2 - Sumário da Parte II: Metodologia da Matemática.

Fonte: Fontoura (1961, p. 197-198).

O autor defendia que a matemática da escola primária deveria ser ensinada essencialmente por práticas, sem fórmulas, abstrações e teorias complicadas, as quais ele exemplifica como sendo os teoremas e corolários. Segundo Fontoura (1961, p. 200), “a Matemática deve ser ensinada para a vida, para solucionar os problemas diários da nossa existência". Nessa perspectiva, o ensino de matemática deveria ter uma razão de ordem prática, com aplicação no cotidiano do aluno.

Para Fontoura (1961), o aprendizado matemático dependia, fundamentalmente, do raciocínio, pois necessita de regras e princípios bem marcados, os quais não poderiam ser modificados pelos professores. Eis que a consequência do não encaminhamento do ensino em obediência de tais regras "é que tantas crianças tomam horror à Matemática pelo resto da vida" (FONTOURA, 1961, p. 201). As regras abordadas pelo autor se referem ao ensino de aritmética, o qual ele chama de "Psicologia da Aritmética".

Há indícios de que as orientações metodológicas contidas no Manual eram baseadas nos princípios da Escola Nova, os quais valorizavam as atividades como jogos. Uma vez que o autor indica o deslocamento do princípio da ação para os alunos, atribuindo-lhes o 
protagonismo nas tarefas e na descoberta dos conhecimentos. Por meio de métodos de projeto e centros de interesse, qualificam a chamada "Escola Ativa", que de acordo com Vidal (2006, p. 11-12), fora criada em 1917, difundindo-se mundialmente a partir de 1922 e apregoada pelos escolanovistas. Frisa-se que é enfatizada pelo autor logo no início de suas orientações sobre a matemática para ensinar e descreve algumas ações que o professor deve seguir para aguçar a motivação da aprendizagem, " a) Partir do concreto; b) Não dar dados absurdos; c) Partir da experiência da criança; d) Partir das atividades infantis na escola; e) Partir sempre que possível de um projeto; f) Estabelecer pesquisas" (FONTOURA, 1961, p. 210211).

As orientações destinadas aos professores, saberes para ensinar matemática, são sequenciais a escolha da motivação, sendo dividida em assuntos. Para o autor, indicam a abordagem que o docente deve realizar, além de trazer algumas sugestões de dinâmicas e jogos, como indicado na Figura 3.

4. Divisão em classes e leitura de números - Para a criança compreender essa árida questão, a mestra deverá concretizá-la, construindo casinhas de papelão, com janelas onde se colocam os algarismos: a casinha das unidades, a casinha dos milhares e a casinha dos milhöes.
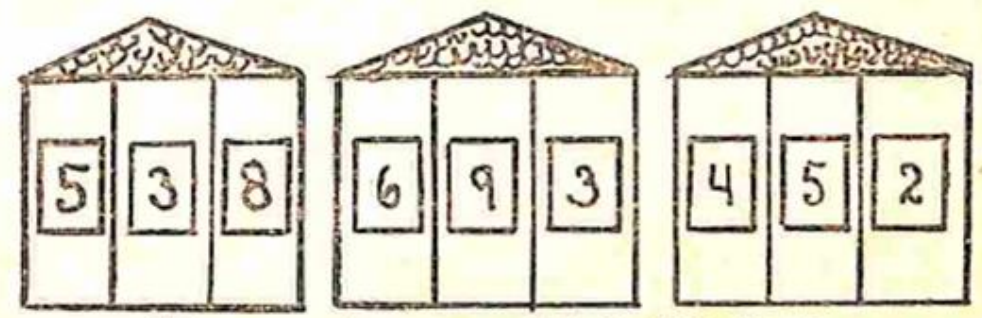

Eis o nútzero 538.693 .452

Figura 3 - Direção da aprendizagem de acordo com o assunto.

Fonte: Fontoura (1961, p. 213).

Outro ponto a observar são os exemplos de questões com enunciados curtos e respostas objetivas, como exemplificado na Figura 4, na qual o autor enfatiza que o ensino inicie pelo "concreto". 


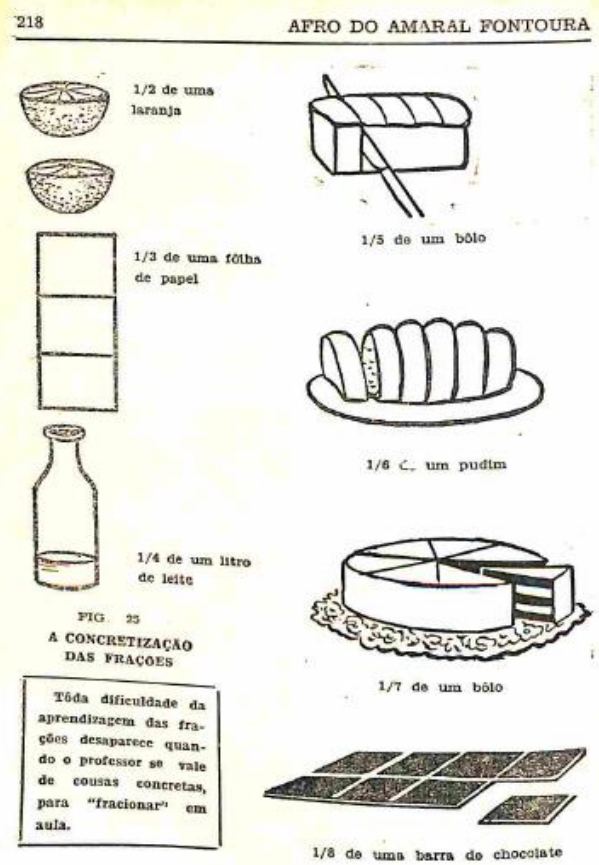

Figura 4 - Concretização do conteúdo a ser ministrado.

Fonte: Fontoura (1961, p. 218).

O autor orienta o professor a desenhar essas figuras no quadro e apresentar aos alunos objetos que possam ser divididos. Afirmando que "toda dificuldade da aprendizagem das frações desaparece quando o professor se vale de coisas concretas, para fracionar em aula" (FONTOURA, 1961, p. 218). Concluindo que na falta de objetos, podem se utilizar de materiais acessíveis como o papelão, com o qual os alunos poderiam desenhar recortar e/ou pintar as partes, representando as frações solicitadas pelo docente.

Ainda segundo o autor, após ter ministrado o conteúdo, o professor deve realizar a verificação da aprendizagem, segundo Fontoura (1961, p. 227) "só existe ensino quando há aprendizagem". A verificação deveria ser realizada por meio da aplicação de exercício, resolução de problemas, aplicação de jogos, discussões (ou debates), resolução de testes e realização de sabatinas, desde que estas não fossem muito longas e cansativas. O professor poderia utilizar uma dessas técnicas, ou mais, se assim julgasse necessário. 


\section{Considerações finais}

A obra de Fontoura traz indícios de que o autor defendeu a importância da formação de professores primários no que se refere à matemática para ensinar, valorizando habilidades profissionais para além do domínio dos conteúdos matemáticos. Destacando saberes para ensinar, o autor reivindicou um conhecimento mais amplo das ciências da educação, especialmente no que diz respeito às contribuições advindas da psicologia da educação, Fontoura considerou novos saberes para conduzir o ensino da matemática escolar, no que se refere aos métodos, processos, formas e modos de planejar, conduzir e avaliar o ensino.

Com a finalização deste estudo, encontramos alguns sinais da expertise de Fontoura, pensamos nele como um indivíduo que conhece o ofício docente e que nele se destacou, tendo um papel fundamental como organizador de manuais que orientariam a formação inicial de futuros docentes. Além de sua atuação em diversas instituições educacionais, com efetiva participação na Associação Brasileira das Escolas Normais e organização de eventos nacionais com escopo de discutir a formação inicial de professores, foi um dos educadores que ajudou na reforma do ensino do Estado da Guanabara.

Cumpre salientar que o professor Afro do Amaral Fontoura foi diretor do Instituto de Educação do Rio de Janeiro e colaborou em outras instâncias, sendo que interviu em diferentes lugares de poder, para os quais era chamado por autoridades a atuar na regulamentação da instrução pública. O que, somado a sua produção de manuais didáticos e atuação docente, o caracteriza como um expert em educação, termo utilizado por Hofstetter; Schneuwly e Freymond (2017).

Quanto aos saberes matemáticos elementares para ensinar, apontados em seu manual Metodologia do Ensino Primário, Fontoura acompanhou o ideário da Escola Nova em relação aos métodos de ensino. Neles se notam estreitas relações da Psicologia com a Pedagogia, condicionando as atividades ao uso de diferentes recursos materiais para serem explorados em sala de aula, tendo em vista o desenvolvimento das potencialidades dos alunos e o melhor alcance da aprendizagem.

Este estudo, ao ambicionar compreender como se articulam os saberes constitutivos do campo profissional docente, colocou em destaque a expertise profissional do educador 
Afro do Amaral Fontoura. Sua obra analisada, ao articular saberes a ensinar com os saberes para ensinar, deixa evidente a objetivação dos saberes profissionais do professor que ensina matemática nos primeiros anos escolares.

\section{Referências}

BERTINI, L. F.; MORAIS, R. S.; VALENTE, W. R. A matemática a ensinar e a matemática para ensinar: novos estudos sobre a formação de professores. São Paulo: Livraria da Física, 2017.

BLOCH, M. Apologia da história ou o ofício do historiador. Tradução: André Telles. Rio de Janeiro: Jorge Zahar, 2002.

CERTEAU, M. A escrita da história. Tradução: Maria de Lourdes Menezes. 2. ed., Rio de Janeiro, RJ: Forense Universitária, 2007.

CHARTIER, R. A história cultural: entre práticas e representações. Lisboa: DIFEL, 1990.

CHERVEL, A. História das disciplinas escolares: reflexões sobre um campo de pesquisa. Teoria \& Educação, Porto Alegre - Pannonica, n. 2, p. 177-229, 1990.

COSTA, D. A.; VALENTE W. R. O repositório de conteúdo digital nas pesquisas de história da Educação matemática, Rev. Iberoam. Patrim. Histórico-Educativo, Campinas-SP, v. 1, n. 1, p. 96110, jul./dez., 2015. Disponível em:

https://econtents.bc.unicamp.br/inpec/index.php/ridphe/article/view/9231. Acesso em: 18 maio de 2018.

FONTOURA, A. A. Metodologia do ensino primário. 6. ed. v. 3. Rio de Janeiro: Editora Aurora, 1961.

FRANÇA, D. M. Biblioteca didática brasileira: o manual de testes e as propostas escolanovistas em cursos de formação de professores (1950-1970). REMATEC, ano 11, n. 23, p. 38-51, set./dez., 2016.

HOFSTETTER, R.; SCHNEUWLY, B. Saberes: um tema central para as profissões do ensino e da formação. In: HOFSTETTER, R.; VALENTE, W. R. (org.). Saberes em (trans)formação: tema central a formação de professores. São Paulo: Editora da Física, 2017, p. 113-172.

HOFSTETTER, R.; SCHNEUWLY, B; FREYMOND, M. Penetrar na verdade da escola para ter elementos concretos de sua avaliação: a irresistível institucionalização do expert em educação (século XIX e XX). In: HOFSTETTER, R.; VALENTE, W. R. (org.). Saberes em (trans)formação: tema central a formação de professores. São Paulo: Editora da Física, 2017. p. 55-112.

HOFSTETTER, R.; VALENTE, W. R. (org). Saberes em (trans)formação: tema central da formação de professores. São Paulo: Editora Livraria da Física, 2017.

JULIA, D. A cultura escolar como objeto histórico. Tradução Gizele de Souza. Revista Brasileira de História da Educação, n. 1, p. 9-43, jan./jun. 2001.

LUSSI BORER, V. Saberes: uma questão crucial para a institucionalização da formação de 
professores. In: HOFSTETTER, R.; VALENTE, W. R. (org.). Saberes em (trans)formação: tema central a formação de professores. São Paulo: Editora da Física, 2017. p. 173-199.

MEUCCI, S. Sobre a rotinização da sociologia no Brasil: os primeiros manuais didáticos, seus autores, suas expectativas. Mediações, Londrina, v. 12, n. 1, p. 31-66, jan./jun., 2007. Disponível em: http://www.uel.br/revistas/uel/index.php/mediacoes/article/viewFile/3386/2758. Acesso em: 10 jul. 2018.

PINTO, N. B. História das disciplinas escolares: reflexão sobre aspectos teórico-metodológicos de uma prática historiográfica. Rev. Diálogo Educ., Curitiba, v. 14, n. 41, p. 125-142, jan./abr. 2014. Disponível em: https://repositorio.ufsc.br/ handle/123456789/160823. Acesso em: 20 mar. 2018.

VALENTE, W. R. Considerações sobre a matemática escolar numa abordagem histórica. Cadernos de História da Educação, n. 3, p. 77-82, jan./dez. 2004. Disponível em: http://www.seer.ufu.br/index.php/che/article/viewFile/363/354. Acesso em: 30 abr. 2018.

VALENTE, W. R. História da Educação Matemática: interrogações metodológicas. REVEMAT, v. 2.2, p. 28-49, UFSC, 2007.

VALENTE, W. R. A educação matemática e os estudos históricos comparativos: de sua legitimidade à sua viabilidade. In: Anais do XIII CIAEM-IACME, Recife, Brasil, 2011. p. 1-9. Disponível em: http://www.lematec.net.br/CDS/XIIICIAEM/artigos/MP1-valente.pdf. Acesso em: 10 jun. 2018.

VALENTE, W. R. O saber: uma questão crucial para a institucionalização da educação matemática e profissionalização do educador matemático. Perspectivas da Educação Matemática, v. 9, n. 20, p. 460-478, 2016.

VALENTE, W. R. A matemática a ensinar e a matemática para ensinar: os saberes para a formação do educador matemático. In: HOFSTETTER, R; VALENTE, W. R. (org.). Saberes em (trans)formação: tema central da formação de professores. Editora Livraria da Física: São Paulo, 2017. p. 113-172.

VIDAL, D. G. Tecendo história (e recriando memória) da escola primária e da infância no Brasil: os grupos escolares em foco. In: VIDAL, D. G. (org.). Grupos escolares: cultura escolar primária e escolarização da infância no Brasil (1893-1971). Campinas: Mercado das Letras, 2006. p. 7-20.

Recebido em: 26/10/2018

Aprovado em: 15/02/2019 